\title{
Predictors Affecting Sexual Anxiety And Marital Satisfaction Among Married Couples
}

\author{
Vidyadayini Shetty ${ }^{1}$, Vaishali Singh ${ }^{2}$ \\ ${ }^{1}$ Associate Professor, Department of Psychology, NK College, Malad, Mumbai. \\ ${ }^{2}$ TYBA Student, Department of Psychology, NK College, Malad, Mumbai. \\ E-mail-vidhi33@gmail.com
}

\begin{abstract}
Background: The purpose of the study was to establish an association between sexual satisfaction and marital satisfaction. The study also aimed to investigate whether demographic factors such as gender, age of the couples, and duration of marriage contributes to marital satisfaction and sexual anxiety.

Methodology: Fifty married couples were recruited through convenient sampling method and were asked to complete the Marital Satisfaction Scale and Sexual Anxiety Scale. The respondents took 20 minutes to fill the self report questionnaire. The researcher helped with clarifications when needed. Descriptive statistical procedures $(\mathrm{M}, \mathrm{SD}$, correlation and t test was calculated on the obtained results.

Results: Pearson's correlation was computed to assess the relationship between sexual anxiety and marital satisfaction. A correlation coefficient of - 0.574 , indicating a statistically significant moderate, negative correlation between sexual anxiety and martial satisfaction ( $\mathrm{r}=-0.574,0.01$ level of significance) was obtained. The mean score of the total sample on sexual anxiety was 31.35 and that of marital satisfaction was 37.34 indicating moderate levels of sexual anxiety and marital satisfaction among males and females. The sexual anxiety scores indicated a significant difference among married males and females $\left(\mathrm{t}{ }_{(98)}=3.60\right.$, $\mathrm{p}<0.01)$ with males having lower anxiety $(\mathrm{M}=28.10)$ as compared to females $(\mathrm{M}=34.60)$.

Conclusion: The study indicates a moderate negative relationship between sexual anxiety and marital satisfaction. There was a significant difference in sexual anxiety among married couples, males having low anxiety as compared to females. The study also indicated that age of the married couple influence sexual anxiety and marital satisfaction. However, gender and duration of marriage affected only sexual anxiety and not marital satisfaction of the married couples.
\end{abstract}

Key Words: Marital satisfaction, sexual anxiety, married couples, gender, duration of marriage.

(Paper received $-26^{\text {th }}$ March 2017, Peer review completed $-10^{\text {th }}$ April 2017, Accepted $-12^{\text {th }}$ April 2017)

\section{INTRODUCTION}

Marriage has been documented in every known culture [1]. More than $90 \%$ of the world's population will marry at least once [2]. Though marriage is a highly desirable relationship, statistics indicate that marital satisfaction is not easily achieved. Marital satisfaction was defined a subjective experience of one's own personal happiness and contentment in the marital relationship [3]. Marital satisfaction is one of the most prominent factors that affect family performance. All couples seek to enjoy their marriage life and experience satisfaction. Compatibility and marital satisfaction is a state in which couples most often feel happy and content with each other; this occurs through mutual love, taking care of one another, acceptance, mutual understanding, and need gratification including sexual needs. The quality of marital relationships is the most studied topic pertaining to marriage and family life. Moreover, clinicians have 
become increasingly interested in this variable as divorce rates have climbed and as services for counseling and therapy have become more readily available and more widely accepted. Marital satisfaction is a complex process that has overtime been thought to be influenced by many factors, including education, socio-economic status, love, commitment, marital communication, conflict, gender, length of marriage, the presence of children, sexual relations and the division of labour [4-6].

Anxiety is an emotion characterized by feelings of tension, worried thoughts and physical changes like increased blood pressure. People with anxiety disorders usually have recurring intrusive thoughts or concerns. They may avoid certain situations out of worry. They may also have physical symptoms such as sweating, trembling, dizziness or a rapid heartbeat [7]. Sexual dysfunctions are a heterogeneous group of disorders that are typically characterized by a clinically significant disturbance in a person's ability to respond sexually or to experience sexual pleasure. Sexual anxiety in the present study is considered as mild to moderate levels of anxiety experienced by couples due the responsibilities of marriage related activities [8-9].

The present study was an attempt to determine the extent of sexual anxiety and marital satisfaction among married couples. The second aim was to establish an association between sexual satisfaction and marital satisfaction. The third aim of this study was to investigate whether demographic factors such as gender, age of the couples, and duration of marriage contributes to marital satisfaction and sexual anxiety. The fourth aim was to determine the gender differences in the four dimensions of sexual anxiety scale.

\section{METHODOLOGY}

\section{Sample}

Pre-determined sample of 50 married couples ranging between 25 to 45 years were approached through convenient sampling method. After stating the purpose of the study and obtaining consent, both scales were administered to the married couples. The respondents took 20 minutes to fill the self report questionnaire. The researcher helped with clarifications when needed.

\section{Hypotheses}

1. There is no relationship between sexual anxiety and marital satisfaction.

2. There is no gender difference in sexual anxiety and marital satisfaction.

3. Age of the couples will not influence sexual anxiety and marital satisfaction.

4. Duration of married life will not influence sexual anxiety and marital satisfaction.

\section{Tools used}

\section{The Marital Satisfaction Scale}

The Marital Satisfaction Scale consists of 30 items. A maximum score possible was 60 and minimum score was 0 . The split half reliability correlating odd even items applying Spearman-Brown formula was 0.94. Test-retest reliability was found to be 0.96 . The validity of the test was found to be 0.77 [10].

\section{Sexual Anxiety Scale}

The Sexual Anxiety Scale consists of 16 highly sensitive items presented in a 4-point rating format. The scale measures four areas: Sexual Potency (SP); Sexual Inhibition (SI); Sexual Attractiveness (SA); and Sexual Monotony (SM). The total score thus varies from 16 to 64 , showing the lowest and the highest levels of sexual anxiety in a person. The scale can also be scored area-wise. The split half reliability, correlating the odd-even items and applying the Spearman-Brown formula for doubling the test length, was found to be $0.88(\mathrm{~N}=40)$, with an index of reliability of 0.93 and test retest reliability was 0.73 [11]. 


\section{STATISTICAL ANALYSIS}

Descriptive statistical procedures were used and $t$ test was calculated along with a correlation to study the relationship between sexual anxiety and marital satisfaction among males and females.

\section{RESULTS}

Pearson's correlation was computed to assess the relationship between sexual anxiety and marital satisfaction. Table 1 indicate a correlation coefficient of -0.574 , indicating a statistically significant moderate, negative correlation between sexual anxiety and martial satisfaction $(r=-0.574,0.01$ level of significance).

Table 1 - Correlations between sexual anxiety and marital satisfaction

\begin{tabular}{|ccc|}
\hline & $\begin{array}{c}\text { Sexual } \\
\text { Anxiety }\end{array}$ & $\begin{array}{c}\text { Marital } \\
\text { Satisfaction }\end{array}$ \\
\hline Sexual Anxiety & 1.00 & \\
\hline Marital Satisfaction & -0.574 & 1.00 \\
\hline
\end{tabular}

${ }^{*}$ correlation significant at 0.01

The mean score of the total sample on sexual anxiety was 31.35 and that of marital satisfaction was 37.34 indicating moderate levels of sexual anxiety and marital satisfaction among males and females. The sexual anxiety scores indicated a significant difference among married males and females $\left(t_{(98)}=3.60, p<0.01\right)$ with males having lower anxiety $(M=28.10)$ as compared to females $(M=34.60)$. However in respect to marital satisfaction, there was no significant difference among married males and females. The mean scores for males was 38.44 and for females 36.24 , indicating a moderate level of martial satisfaction.

Table 2 - Mean, SD, p values of demographic variables on sexual anxiety and marital satisfaction

\begin{tabular}{|c|c|c|c|c|c|}
\hline \multicolumn{4}{|c|}{ Sexual Anxiety scale } & \multicolumn{2}{|c|}{ Marital Satisfaction scale } \\
\hline & $\mathbf{N}$ & Mean & SD & Mean & SD \\
\hline & 100 & 31.35 & 9.55 & 37.34 & 9.88 \\
\hline \multicolumn{6}{|c|}{ Gender } \\
\hline $\mathbf{M}$ & 50 & 28.10 & 9.05 & 38.44 & 9.66 \\
\hline $\mathbf{F}$ & 50 & 34.60 & 8.99 & 36.24 & 10.07 \\
\hline $\mathrm{t}$ value & \multicolumn{2}{|c|}{-3.60} & & \multicolumn{2}{|c|}{1.11} \\
\hline p value & \multicolumn{2}{|c|}{$0.0005^{*}$} & & \multicolumn{2}{|c|}{$0.2678 \mathrm{NS}$} \\
\hline \multicolumn{6}{|c|}{ Age of couples } \\
\hline $25-35$ & 50 & 34.58 & 9.86 & 34.94 & 8.54 \\
\hline $36-40$ & 50 & 28.12 & 8.11 & 39.74 & 10.61 \\
\hline$t$ value & \multicolumn{2}{|c|}{3.58} & & \multicolumn{2}{|c|}{-2.49} \\
\hline p value & \multicolumn{2}{|c|}{$0.0005^{*}$} & & \multicolumn{2}{|c|}{0.0144} \\
\hline \multicolumn{6}{|c|}{ Duration of marriage } \\
\hline$>$ than 10 yrs & 64 & 32.97 & 9.75 & 36.72 & 9.39 \\
\hline$<$ than 10 yrs & 36 & 28.47 & 8.58 & 38.44 & 10.75 \\
\hline t value & \multicolumn{2}{|c|}{2.31} & & \multicolumn{2}{|c|}{-0.84} \\
\hline p value & \multicolumn{2}{|c|}{$0.0230^{*}$} & & \multicolumn{2}{|c|}{$0.4047 \mathrm{NS}$} \\
\hline
\end{tabular}

${ }^{*}$ significant $(\mathrm{p}<0.05), \mathrm{NS}-$ not significant 
The analysis of the various dimensions of the sexual anxiety scale indicated a significant difference among males and females in the area of sexual potency $\left(\mathrm{t}{ }_{(98)}=4.16, \mathrm{p}<0.01\right)$ and sexual inhibition $\left(\mathrm{t}{ }_{(98)}=3.23, \mathrm{p}\right.$ $<0.01)$. Sexual potency and sexual inhibition were found to be higher among females as compared to males. There were no significant differences among males and females in the area of sexual attractiveness and sexual monotony (Table 3).

The findings of the study explored the level of sexual anxiety and marital satisfaction in reference to the age of married couples. The findings indicated that couples between $25-35$ years of age experience higher levels of anxiety $(M=34.58)$ than couples between $36-45$ years of age $(28.12)$. The obtained value $\left(t_{(98)}=\right.$ $3.58, \mathrm{p}$ value $=0.0005$ ) indicated a statistically significant difference in the sexual anxiety scores among both age groups. Marital satisfaction for both the age groups was also found to be statistically significant, with older married couples experiencing more satisfaction as compared to younger married couples.

Table 3 - Mean, SD, p value of all the dimensions on sexual anxiety scale of males and females

\begin{tabular}{|c|c|c|c|c|}
\hline & Sexual Potency & Sexual Inhibition & Sexual Attractiveness & Sexual Monotony \\
\hline & Mean SD & Mean SD & Mean SD & Mean SD \\
\hline Males & $13.76 \quad 4.48$ & $6.92 \quad 2.80$ & $3.64 \quad 1.52$ & $\begin{array}{ll}3.78 & 1.81\end{array}$ \\
\hline Females & $17.48 \quad 4.45$ & $\begin{array}{ll}8.70 & 2.70\end{array}$ & $\begin{array}{ll}4.02 & 1.49\end{array}$ & $\begin{array}{ll}4.36 & 1.38\end{array}$ \\
\hline t value & -4.16 & -3.23 & -1.27 & -1.80 \\
\hline p value & $0.0001^{*}$ & $0.0017^{*}$ & $0.2083^{\mathrm{NS}}$ & $0.0748^{\mathrm{NS}}$ \\
\hline
\end{tabular}

*significant $(p<0.05), \mathrm{NS}-$ not significant

The study also investigated the effect of duration of marriage on sexual anxiety and martial satisfaction. The mean score on sexual anxiety for couples with less than 10 years of marriage was 32.97 and 28.47 for more than 10 years of marriage. The $t$ value of sexual anxiety of couples married for more than ten years or less, indicated a statistically significant difference $\left(\mathrm{t}{ }_{(98)}=2.31, \mathrm{p}\right.$ value $\left.=.0230\right)$. However, the marital satisfaction score showed no significant difference in younger and married couples.

\section{DISCUSSION}

The mean scores of sexual anxiety and martial satisfaction was found to be of moderate levels among married males and females. Pearson's correlation results indicated a statistically significant moderate, negative correlation between sexual anxiety and martial satisfaction indicating that as sexual anxiety increases among married couples, martial satisfaction will be lowered.

An important variable related to marital satisfaction is gender. Gender differences have been reported in the marital satisfaction literature, but the findings are mixed. The findings indicated a significant gender differences among married males and females in the scores on sexual anxiety. Wives reported more anxiety than husbands. Results indicated no difference in the levels of marital satisfaction in husbands and wives. The study reflect that there other variables besides sexual intimacy that influence martial satisfaction. Marital satisfaction research has resulted in the identification of a multitude of factors that contribute to a satisfactory marital union. These factors include feelings of love, trust, respect and fidelity [12-13], social support, and commitment, equity of tasks, gender roles, and sexual interaction [14-16].

The present study examined the gender differences in the four dimensions of sexual anxiety scale. The four dimensions measured were: Sexual Potency (SP); Sexual Inhibition (SI); Sexual Attractiveness (SA); and Sexual Monotony (SM). Sexual inhibition refers to conscious or subconscious constraint or curtailment by a person of behaviour relating to specific sexual matters or practices or of a discussion of sexual matters. Sexual potency refers to the ability to carry out and consummate sexual intercourse, usually referring to the male. Sexual attraction is attraction on the basis of sexual desire or the quality of arousing such interest. Sexual monotony refers to the practice of restricting oneself to having sex with only one other person [17]. The analysis of the various dimensions of the scale indicated a significant difference among males and females in the area of sexual potency and sexual inhibition. Sexual potency and sexual 
inhibition were found to be higher among females as compared to males, which was highly surprising. There were no significant differences among males and females in the area of sexual attractiveness and sexual monotony.

The study explored the influence of age of couples on sexual anxiety and marital satisfaction. Results indicated significant difference in sexual anxiety and marital satisfaction in association with the ages of the married couples. The findings signify that as the couple age, the maturity level to deal with sexual anxiety also increases thereby increasing martial satisfaction. An assumption may be that with the growing responsibilities of children and other family related issues, the problems with sexual anxiety take a back seat or maybe suppressed and fulfilling these responsibilities results in greater martial satisfaction [18-19].

Analysis of results with reference to duration of marriage indicated that as marriage progress, less the sexual anxiety experienced by married couples. However, duration of marriage did not indicate any significant difference in the marital satisfaction. Findings from past research have indicated that a person's satisfaction with his/her marriage plays a very important part in his/her overall happiness and sexual satisfaction has an important part to play in marital satisfaction [20].

\section{REFERENCES}

1. Brown SL, Booth A. Cohabitation versus marriage: A comparison of relationship quality. J Marr Family 1996;11:668-78.

2. Javanmard GH, Garegozlo RM. The Study of Relationship between Marital Satisfaction and Personality Characteristics In Iranian Families. Proc Soc Behav Sci 2013;84:396-9.

3. Hendrick S, Hendrick C. Liking, loving and relating. Brooks/Cole Pub Co; 1992.

4. Bradbury TN, Fincham FD, Beach SR. Research on the nature and determinants of marital satisfaction: A decade in review. J Marr Family 2000;62(4):964-80.

5. Twenge JM, Campbell WK, Foster CA. Parenthood and marital satisfaction: a meta-analytic review. J Marr Family 2003;65(3):574-83.

6. Karney BR, Bradbury TN. The longitudinal course of marital quality and stability: A review of theory, methods, and research. Psychol Bull 1995;118(1):3-15.

7. Beck AT, Emery G, Greenberg RL. Anxiety disorders and phobias: A cognitive perspective. Basic Books; 2005.

8. Beggs VE, Calhoun KS, Wolchik SA. Sexual anxiety and female sexual arousal: A comparison of arousal during sexual anxiety stimuli and sexual pleasure stimuli. Arch Sex Behav 1987;16(4):311-9.

9. Young M, Denny G, Luquis R, Young T. Correlates of sexual satisfaction in marriage. Can J Hum Sexuality 1998;7(2):115-25.

10. Amruthraj B, Prakash IJ. Development of a marital satisfaction scale. Psychol Stud 1985;30(2):124-8.

11. Kumar P. Manual for sexual anxiety scale. Department of Psychology, Sardar Patel University, Vallabh Vidyanagar; 1992.

12. Sharlin S, Kaslow FW, Hammerschmidt H. Together through thick and thin: A multinational picture of long-term marriages. Haworth Press; 2000.

13. Litzinger S, Gordon KC. Exploring relationships among communication, sexual satisfaction, and marital satisfaction. J Sex Marital Ther 2005;31(5):409-24.

14. Karney BR, Bradbury TN. Neuroticism, marital interaction, and the trajectory of marital satisfaction. J Personal Soc Psychol 1997;72(5):1075-80.

15. Fincham FD, Beach SR, Harold GT, Osborne LN. Marital satisfaction and depression: Different causal relationships for men and women?. Psychol Sci 1997;8(5):351-6.

16. Jackson JB, Miller RB, Oka M, Henry RG. Gender differences in marital satisfaction: A meta-analysis. J Marr Family 2014;76(1):105-29.

17. Chambless DL, Lifshitz JL. Self-reported sexual anxiety and arousal: The expanded sexual arousability inventory. J Sex Res 1984;20(3):241-54.

18. Fincham FD, Harold GT, Gano-Phillips S. The longitudinal association between attributions and marital satisfaction: Direction of effects and role of efficacy expectations. J Fam Psychol 2000;14(2):267-83.

19. Fincham FD. Marital conflict correlates, structure, and context. Current Directions in Psychol Sci 2003;12(1):23-7. 
20. Rogers SJ, White LK. Satisfaction with parenting: The role of marital happiness, family structure, and parents' gender. J Marr Family 1998;2(2):293-308.

$* * * * * * * * * * * * * * * * * * * * * * * * * * * * * * * *$

Acknowledgements - Nil

Source of Funding - Nil

Conflict of Interest $-\mathrm{Nil}$

\section{Block your dates $-23^{\text {il }}-26^{\text {IIt }}$ Auginnt 2018}

\section{Indian Association of Biological Psychiatry (IABP)}

Presents

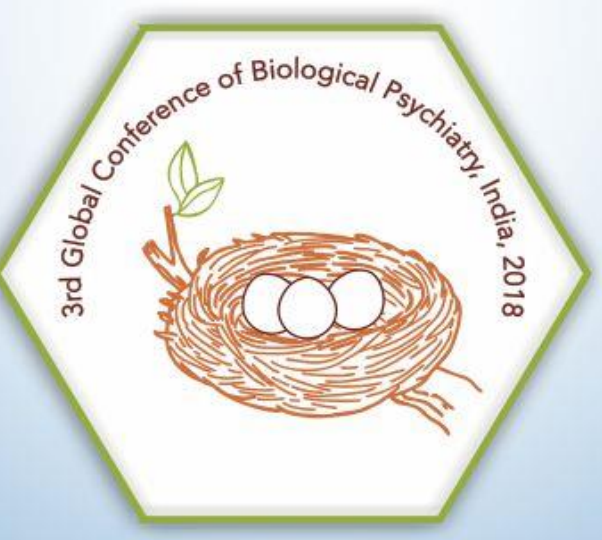

Theme:

Translational Neurobiology and Clinical Psychiatry

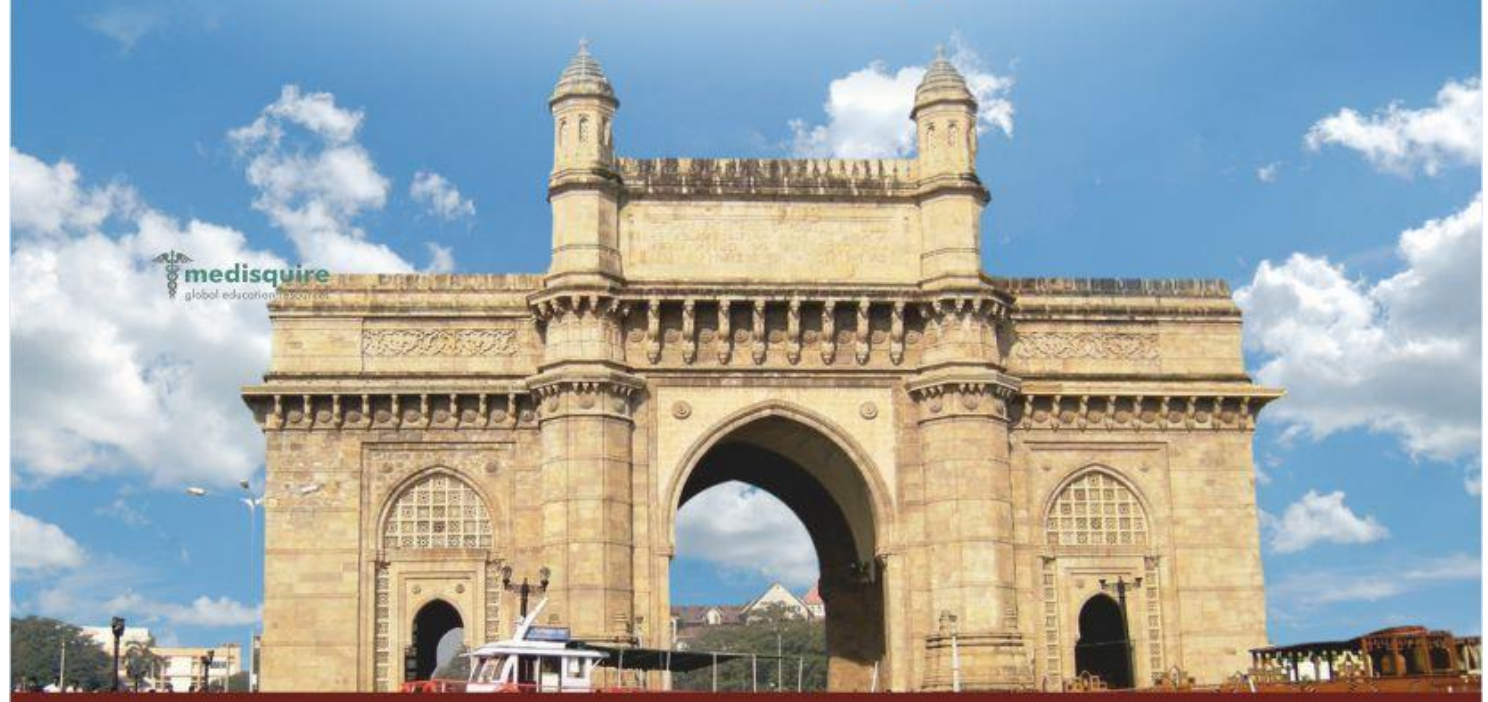

To register : Call - +02261053811/12 or Email - info@medisquire.com 